\title{
The protective effects of cerium oxide nanoparticles against hepatic oxidative damage induced by monocrotaline
}

This article was published in the following Dove Press journal:

International Journal of Nanomedicine

I4 January 20 I I

Number of times this article has been viewed

\author{
Kamal A Amin' \\ Mohamed S Hassan ${ }^{2}$ \\ El-Said T Awad ${ }^{3}$ \\ Khalid S Hashem' \\ 'Department of Biochemistry, \\ ${ }^{2}$ Department of Internal Medicine, \\ Faculty of Veterinary Medicine, \\ Beni-Suef University, Beni-Suef, \\ Egypt; ${ }^{3}$ Department of Biochemistry, \\ Faculty of Veterinary Medicine, Cairo \\ University, Cairo, Egypt
}

Objective: The objective of the present study was to determine the ability of cerium oxide $\left(\mathrm{CeO}_{2}\right)$ nanoparticles to protect against monocrotaline (MCT)-induced hepatotoxicity in a rat model.

Method: Twenty male Sprague Dawley rats were arbitrarily assigned to four groups: control (received saline), $\mathrm{CeO}_{2}$ (given $0.0001 \mathrm{nmol} / \mathrm{kg}$ intraperitoneally [IP]), MCT (given $10 \mathrm{mg} / \mathrm{kg}$ body weight IP as a single dose), and $\mathrm{MCT}+\mathrm{CeO}_{2}$ (received $\mathrm{CeO}_{2}$ both before and after $\mathrm{MCT}$ ). Electron microscopic imaging of the rat livers was carried out, and hepatic total glutathione (GSH), glutathione reductase (GR), glutathione peroxidase (GPX), glutathione S-transferase (GST), superoxide dismutase (SOD), and catalase (CAT) enzymatic activities were quantified.

Results: Results showed a significant MCT-induced decrease in total hepatic GSH, GPX, GR, and GST normalized to control values with concurrent $\mathrm{CeO}_{2}$ administration. In addition, $\mathrm{MCT}$ produced significant increases in hepatic CAT and SOD activities, which also ameliorated with $\mathrm{CeO}_{2}$.

Conclusions: These results indicate that $\mathrm{CeO}_{2}$ acts as a putative novel and effective hepatoprotective agent against MCT-induced hepatotoxicity.

Keywords: monocrotaline, ceruim oxide nanoparticle, hepatotoxicity, oxidative stress

\section{Introduction}

A recent increase in interest in and use of bioreactive nanoparticles represents a new era in the intersection of nanotechnology and biotechnology. These studies have revealed a growing realization of the potential utility of novel environmentally benign technologies in diagnosis and therapeutic use in biological systems.

Most recently, cerium oxide $\left(\mathrm{CeO}_{2}\right)$ nanoparticles have been tested for their ability to serve as free radical scavengers ${ }^{1,2}$ to provide protection against chemical, biological, and radiological insults that promote the production of free radicals. The chemistry of engineered $\mathrm{CeO}_{2}$ nanoparticles supports its potential role as a safe and effective biological free radical scavenger or antioxidant. The intracellular $\mathrm{CeO}_{2}$ nanoparticles promote cell longevity and decrease toxic insults by virtue of their antioxidant effects, ${ }^{3}$ preventing the accumulation of reactive oxygen species (ROS) and reducing the activation of the apoptotic response and death of the cells. ${ }^{4}$ In previous studies, $\mathrm{CeO}_{2}$ nanoparticles showed no toxic effect on normal breast epithelial (CRL 8798) cells and only a slight effect on breast cancer (MCF-7) cells at concentrations $>50 \mathrm{nM} .{ }^{5}$ Furthermore, $\mathrm{CeO}_{2}$ selectively conferred radioprotection to the normal cells (CRL 8798) as compared with the tumor cells (MCF-7). ${ }^{5}$
Correspondence: Kamal A Amin Department of Biochemistry, Faculty of Veterinary Medicine, Beni-Suef University, Beni-Suef 625II, Egypt Tel +20822327982

Fax +20822327982

Email kaamin10@yahoo.com 
In this study, $\mathrm{CeO}_{2}$ was chosen because of its free radical scavenging activity. ${ }^{6}$ The metal oxide is a nonstoichiometric compound with the cerium atom characterized by both +4 and +3 oxidation states and possesses a cubic fluorite structure. Recent research using X-ray photoelectron spectroscopy and X-ray absorption near-edge spectroscopy suggests that the concentration of $\mathrm{Ce}^{3+}$ relative to $\mathrm{Ce}^{4+}$ increases as particle size decreases, with a conservative $\left(\mathrm{Ce}^{3+}\right)$ minimum of $6 \%$ in $6 \mathrm{~nm}$ nanoparticles and $1 \%$ in $10 \mathrm{~nm}$ particles. ${ }^{7}$ This dual oxidation state means that these nanoparticles have oxygen vacancies. ${ }^{8}$ The loss of oxygen and the reduction of $\mathrm{Ce}^{4+}$ to $\mathrm{Ce}^{3+}$, shown in Figure 1, are accompanied by creation of an oxygen vacancy. This property is responsible for the interesting redox chemistry exhibited by ceria nanoparticles and makes them attractive for catalytic applications.

Monocrotaline (MCT), a plant-derived pyrrolizidine alkaloid (PA), causes oxidative veno-occlusive disease of the liver, which is thought to be predominantly due to the hepatic formation of a pyrrolic metabolite. Several studies have shown that this metabolite may be detoxified by conjugation with the free radical scavenger reduced glutathione (GSH).

Human exposure occurs from consumption of contaminated grains, herbal teas, and medicines. Intraperitoneal (IP) injection of MCT in rats produced time-dependent hepatic parenchymal cell injury beginning at $12 \mathrm{~h} .{ }^{9}$ Thus, the animal and human health risk posed by exposure to PAs is of great concern. ${ }^{4}$

To date, about 660 PAs and their $N$-oxide derivatives have been identified, and at least half are toxic. ${ }^{10,11}$ There are three major types of PAs: heliotridenes, retronecines, and otonecines. In general, many studies consider that PAs should be metabolized in vivo, predominantly in the liver through cytochrome P450 enzyme systems to form toxic pyrrole metabolites (Figure 2)..$^{12,13}$

MCT is a retronecine-type PA that is present in various species of leguminous Crotalaria plants. MCT exposure has been responsible for numerous outbreaks of poisoning worldwide. ${ }^{14}$ Typically, exposed people develop hepatomegaly and veno-occlusive disease of the liver. In nonhuman primates and a variety of other species, MCT also causes pulmonary arterial hypertension and right ventricular hypertrophy. ${ }^{15}$ MCT undergoes hepatic bioactivation to the reactive pyrrole dehydromonocrotaline. It is believed that the release of reac-

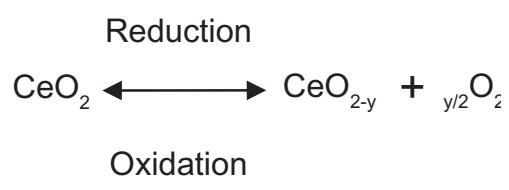

Figure I The oxidation and reduction reactions of cerium oxide $\left(\mathrm{CeO}_{2}\right)$ nanoparticles. tive dehydromonocrotaline from the liver is responsible for toxicity to extrahepatic organs, such as the heart and lungs. Dehydromonocrotaline is detoxified by conjugation with GSH. ${ }^{16}$ Thus, the toxicity of MCT is affected by the GSH status of the liver. MCT, in turn, influences the metabolism of GSH and related sulfur-containing compounds. ${ }^{17}$ Within $24 \mathrm{~h}$ of exposing rats to MCT or related PAs, there is a change in sulfur amino acid metabolism from the cysteine-taurine axis to the cysteine + GSH axis. ${ }^{17,18}$ Many studies report a marked decrease in the hepatic GSH level in rats treated with MCT when compared with the control group. ${ }^{19}$

Dehydromonocrotaline can alkylate cell macromolecules in the liver, with such alkylation probably representing the biochemical basis of its toxicity. ${ }^{20,21}$ It can also be released into the circulation to bind covalently to macromolecules in extrahepatic organs. ${ }^{17,20}$ The amount of dehydromonocrotaline available for these presumably intoxicating pathways is affected markedly by the GSH content of the liver. ${ }^{22}$ GSH conjugates with dehydromonocrotaline to form glutathione dehydropyrrolizidine (GSDHP), a compound of much lower toxicity that is released in high concentration into the bile. ${ }^{20}$ Sulfur amino acids, such as methionine and cysteine, that elevate hepatic GSH content also protect against PA toxicity. ${ }^{23,24}$

Nanoparticles may offer a novel therapeutic alternative for scavenging environmentally elevated ROS. In this study, the use of nanoparticle-based antioxidants as a potential treatment for hepatotoxicity, which is a life-threatening problem, was explored. One obvious use of the nanoparticles would be for enhancing the performance of antioxidants. Therefore, the aims of this study were to design a rat model for hepatotoxicity and to determine the extent to which rare earth $\mathrm{CeO}_{2}$ nanoparticles safeguard against MCT-induced hepatotoxicity in the model.

\section{Material and methods}

This study was approved by the Committee of Scientific Ethics at Beni-Suef University, Egypt, and was carried out in accordance with its guidelines for animal use.

\section{Chemicals}

MCT was purchased from Toronto Research Chemicals Inc. (North York, Canada) in a synthetic form (MCT pyrrole, 3,8-didehydromonocrotaline; $\mathrm{C}_{16} \mathrm{H}_{21} \mathrm{NO}_{6}$ ). $\mathrm{CeO}_{2}$ nanoparticles ( $>25 \mathrm{~nm}$ particle size, $10 \mathrm{wt} \%$ in $\mathrm{H}_{2} \mathrm{O}$ ) were obtained from Sigma-Aldrich (St Louis, MO, USA). GSH and glutathione S-transferase (GST) assay kits were obtained from Sigma-Aldrich. Glutathione reductase (GR), catalase (CAT), glutathione peroxidase (GPX), and superoxide 


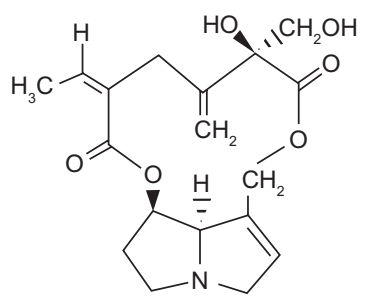

Riddelline

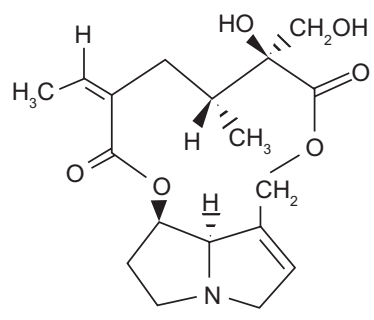

Retrorsine

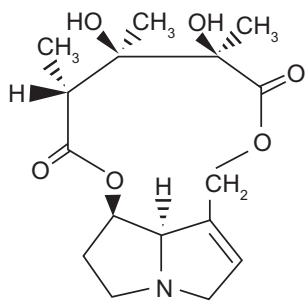

Monocrotaline

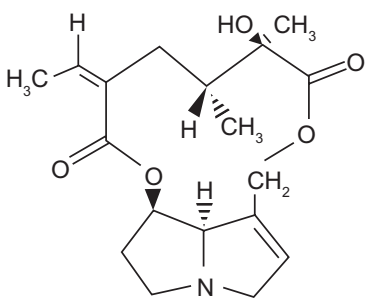

Senecionine

Figure 2 Nomenclatures and structures of the tumorigenic retronecine-type pyrrolizidine alkaloids. ${ }^{13}$

dismutase (SOD) assay kits were purchased from Fisher Scientific Company (LLC, San Diego, CA, USA).

\section{Animals}

Twenty male Sprague Dawley rats ( $\mathrm{n}=5$ per group; housed two to three per cage) were acclimated for 2 weeks prior to the study, at optimal temperature $\left(22^{\circ} \mathrm{C}\right)$, light $(14-10 \mathrm{~h}$ light-dark schedule), and humidity ( $40 \%-60 \%)$.

\section{Treatment protocol}

Following acclimation, rats were arbitrarily assigned to one of the four following treatment groups, dosed, and euthanized by carbon dioxide asphyxiation $24 \mathrm{~h}$ following final injection: 1) control: rats in this group received a single dose of sterile phosphate-buffered physiological saline (PBS; $0.5 \mathrm{~mL} \mathrm{IP}$ ); 2) $\mathrm{CeO}_{2}$ : rats in this group received $\mathrm{CeO}_{2}(0.00001 \mathrm{mg} / \mathrm{kg}$; $0.5 \mathrm{~mL}$ in PBS IP) on days 1 and 3; 3) MCT: rats in this group received a single dose of MCT $(10 \mathrm{mg} / \mathrm{kg}$ body weight in $0.5 \mathrm{~mL}$ PBS IP); and 4) $\mathrm{MCT}+\mathrm{CeO}_{2}$ : rats in this group received $\mathrm{CeO}_{2}$ (as before) on days 1,3,5, and 7 and a single dose of MCT (as before) on day 4. Concurrent $\mathrm{CeO}_{2}$ $(0.0001 \mathrm{nmol} / \mathrm{kg}$ in $0.5 \mathrm{~mL}$ PBS IP) was administered both before and after MCT administration. MCT with or without concurrent $\mathrm{CeO}_{2}$ effects was evaluated.

\section{Hepatic cytosolic and mitochondrial extract preparation}

The liver was rinsed with cold PBS to remove excess blood. Small portions of the liver from $\mathrm{CeO}_{2}$ treatment groups were preserved in glutaraldehyde and subjected to electron microscopic examination using conventional methods. This was performed to ensure homogeneous distribution of ceria and to demonstrate no adverse effects of $\mathrm{CeO}_{2}$ alone on hepatocellular health and architecture. The remaining liver samples from each treatment group were minced in $10 \%(\mathrm{w} / \mathrm{v}) 0.1 \mathrm{M} \mathrm{PBS}(\mathrm{pH} 7.4)$ and homogenized using a Teflon Homogenizer (Tissue Tearor, BioSpec Products Inc, Bartlesville, OK, USA). The homogenate was centrifuged at $4000 \mathrm{rpm}$ for $30 \mathrm{~min}$ at $4^{\circ} \mathrm{C}$ to separate supernatant from cellular debris. The supernatant was then used for the estimation of GSH, GR, GST, SOD, CAT, and GPX.

\section{Statistical analysis}

Statistical analysis was carried out using GraphPad InStat software (version 3, ISS, Rome, Italy), and one-way analysis of variance followed by Tukey-Kramer multiple comparison post hoc test were used to establish significant differences between groups (see Table 1 and Table 2).

\section{Results}

Electron microscopic examination of liver samples from rats receiving $\mathrm{CeO}_{2}$ alone demonstrated a homogeneous intrahepatocellular distribution of nanoparticles (Figure 3A-C) without phenotypic alteration of hepatocellular architecture. Liver samples obtained from the $\mathrm{CeO}_{2}+\mathrm{MCT}$ group also demonstrated regular intracellular distribution of nanoparticles and, importantly, did not exhibit alterations in cellular morphology, which is likely to be due to $\mathrm{CeO}_{2}$ protection against MCT-elevated oxidative damage to the liver.

Table I Changes in hepatic cytosolic and mitochondrial GR, GSH, GST, and GPX activities in different groups

\begin{tabular}{lllll}
\hline Group & GR $(\mathbf{n m o l} / \mathbf{m i n} / \mathbf{m L})$ & GSH $(\mu \mathbf{m o l} / \mathbf{m L})$ & GST $(\mathbf{n m o l} / \mathbf{m i n} / \mathbf{m L})$ & GPX $(\mathbf{n m o l} / \mathbf{m i n} / \mathbf{m L})$ \\
\hline Control & $507.8 \pm 27.48^{\mathrm{a}}$ & $5.40 \pm 0.59^{\mathrm{a}}$ & $15.66 \pm 1.55^{\mathrm{a}}$ & $129.4 \pm 17.42^{\mathrm{a}}$ \\
$\mathrm{CeO}_{2}$ & $572.9 \pm 26.06^{\mathrm{a}}$ & $5.49 \pm 0.72^{\mathrm{a}}$ & $16.85 \pm 1.55^{\mathrm{a}}$ & $340.9 \pm 17.93^{\mathrm{b}}$ \\
$\mathrm{MCT}$ & $115.5 \pm 4.6^{\mathrm{b}}$ & $1.34 \pm 0.099^{\mathrm{b}}$ & $1.31 \pm 0.35^{\mathrm{b}}$ & $27.12 \pm 1.01^{\mathrm{c}}$ \\
$\mathrm{MCT}+\mathrm{CeO}_{2}$ & $489.6 \pm 19.98^{\mathrm{a}}$ & $6.34 \pm 0.20^{\mathrm{a}}$ & $13.9 \pm 2.5^{\mathrm{a}}$ & $113.1 \pm 16.04^{\mathrm{a}}$ \\
\hline
\end{tabular}

Notes: ${ }^{a-c}$ Different superscripts indicate significance at $P<0.05$. Values are expressed as means $\pm \mathrm{SEM}$.

Abbreviations: GR, glutathione reductase; GSH, glutathione; GST, glutathione S-transferase; GPX, glutathione peroxidase; CeO ${ }_{2}$, cerium oxide; $\mathrm{MCT}_{\text {, monocrotaline; }}$ SEM, standard error of mean. 
Table 2 Changes in hepatic CAT and SOD in different groups

\begin{tabular}{lll}
\hline Group & CAT (nmol/min/mL) & SOD (unit/g protein) \\
\hline Control & $13.19 \pm 0.54^{\mathrm{a}}$ & $12.42 \pm 0.29^{\mathrm{a}}$ \\
$\mathrm{CeO}_{2}$ & $13.20 \pm 0.49^{\mathrm{a}}$ & $16.21 \pm 1.02^{\mathrm{a}}$ \\
$\mathrm{MCT}$ & $24.68 \pm 0.82^{\mathrm{b}}$ & $29.11 \pm 0.35^{\mathrm{b}}$ \\
$\mathrm{CeO}_{2}+\mathrm{MCT}$ & $14.16 \pm 0.48^{\mathrm{a}}$ & $11.59 \pm 0.80^{\mathrm{a}}$ \\
\hline
\end{tabular}

Notes: ${ }^{\mathrm{a}, \mathrm{b}}$ Different superscripts indicate significance at $P<0.05$. Values are expressed as means \pm SEM.

Abbreviations: CAT, catalase; SOD, superoxide dismutase; $\mathrm{CeO}_{2}$, cerium oxide; MCT, monocrotaline; SEM, standard error of mean.

Figure $3 \mathrm{~A}$ shows $\mathrm{CeO}_{2}$ nanoparticles intracellularly in the endosomes, cytoplasm with no abnormal vaculation, and regular distribution of $\mathrm{CeO}_{2}$ within normal lysosomes. Figure 3B illustrates hepatocyte organelles (mitochondria) with a normal structure and regular distribution of $\mathrm{CeO}_{2}$ with homogenous size all over the cytoplasm; furthermore, Figure $3 \mathrm{C}$ demonstrates normal ribosomes (rough endoplasmic reticulum).

\section{Changes of hepatic oxidative/ antioxidative parameters}

Changes in hepatic cytosolic and mitochondrial GSH, GR, GPXs, and GST activities

Rats given a single dose of MCT showed a significant decrease in total GSH, as well as GR, GPX, and GST

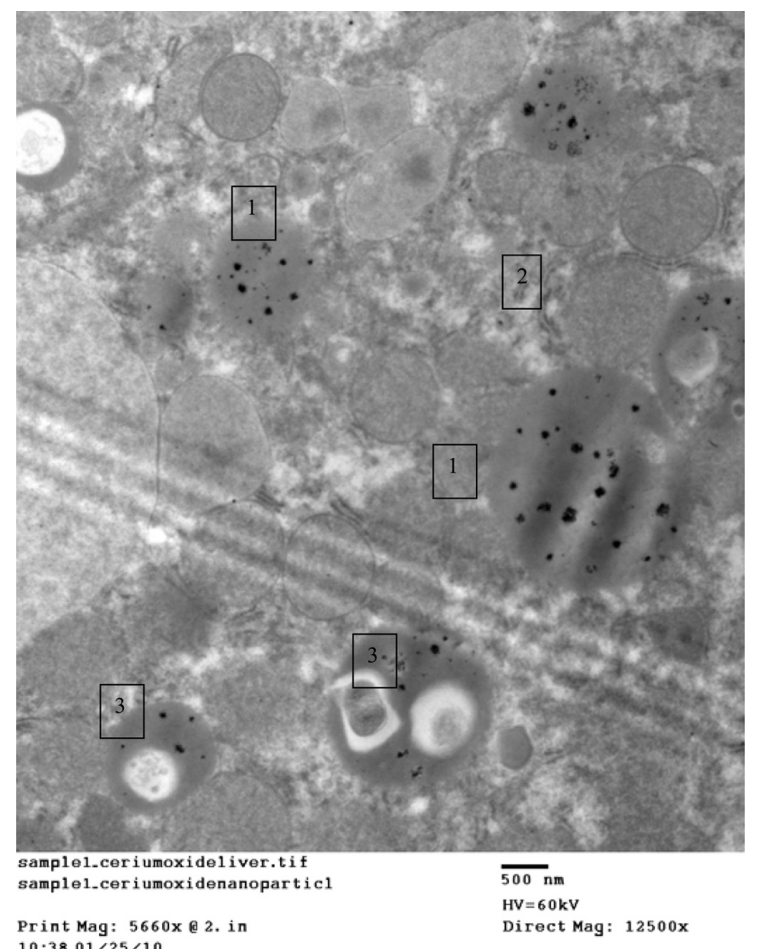

Figure 3A I) Regular distribution of cerium oxide $\left(\mathrm{CeO}_{2}\right)$ nanoparticles intracellular in the endosomes. 2) Homogenous appearance of cytoplasm with no abnormal vaculation, original magnification $\times 12,500$. 3) Regular distribution of $\mathrm{CeO}_{2}$ nanoparticles within normal lysosomes.

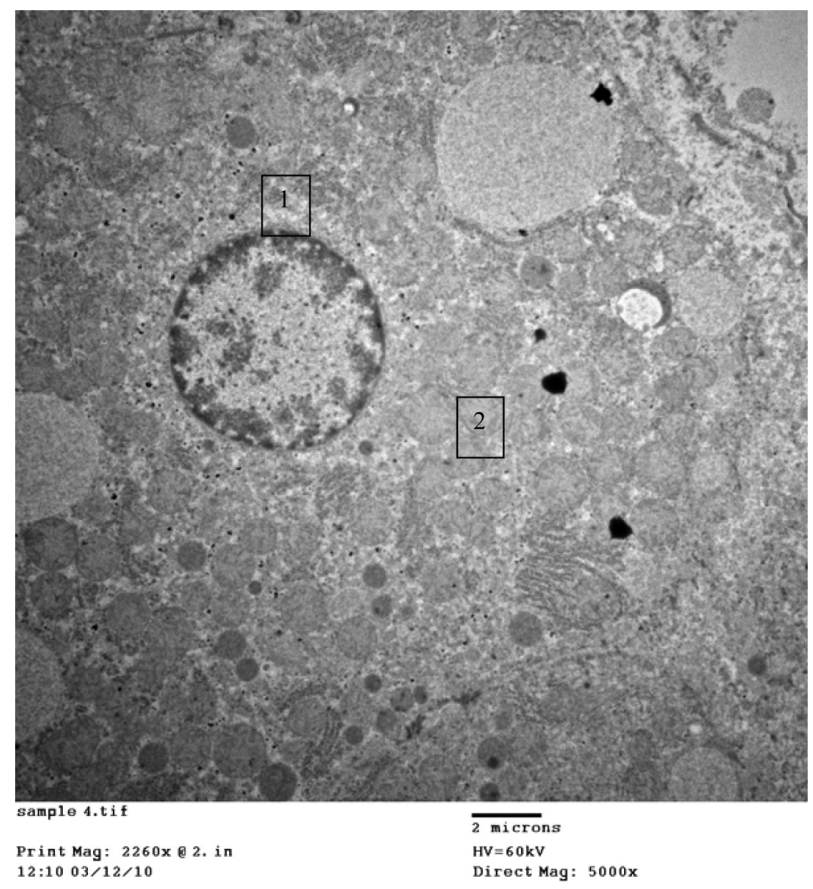

Figure 3B I) Hepatocytes organelles (mitochondria) showing normal structure. 2) Regular distribution of cerium oxide nanoparticles with homogenous size all over the cytoplasm, original magnification $\times 5000$.

activities compared with the control group. Concurrent administration of $\mathrm{CeO}_{2}+\mathrm{MCT}$ restored total GSH, GR, and GST activities to near control levels, suggesting that $\mathrm{CeO}_{2}$ may serve as an effective therapy against hepatic oxidative damage caused by MCT (Table 1).

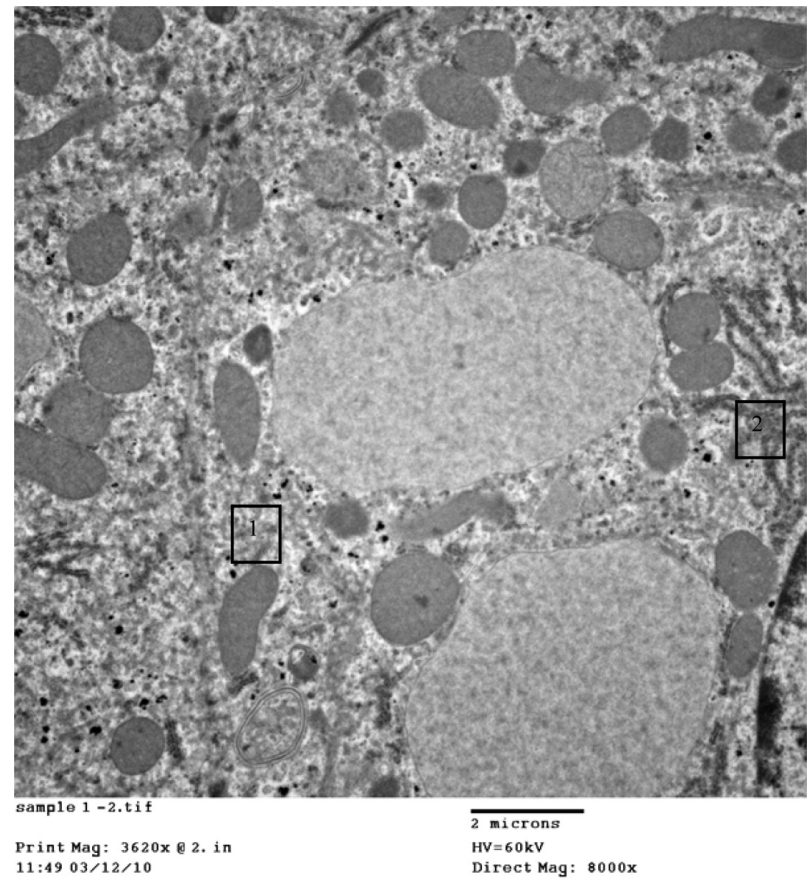

Figure 3C I) Even distribution of cerium oxide over the cytoplasm of the hepatocytes. 2) Normal ribosomes (rough endoplasmic reticulum), original magnification $\times 8000$. 


\section{Changes in hepatic CAT and SOD activities}

Rats given a single dose of MCT showed a significant increase in hepatic CAT and SOD activities compared with control rats; concurrent administration of $\mathrm{CeO}_{2}$ before and after MCT, as previously described, similarly normalized CAT and SOD to near control levels (Table 2).

\section{Visual effects of systemic nanoparticle application on rat models}

No visible toxicity was observed for the route of administration, and beneficial properties were observed for the nanoparticle treatments as well.

\section{Discussion}

MCT is a toxic PA that is globally distributed and found naturally in arid plants such as Crotalaria spp. Toxicity is caused by bioactivation of MCT in the liver to the reactive alkylating pyrrole dehydromonocrotaline. Such a mechanism was suggested in 1968 by Mattocks ${ }^{25}$ and was recently verified with the isolation of dehydromonocrotaline from incubations of rat liver microsomes. ${ }^{26}$

Dehydromonocrotaline is released from isolated liver samples perfused with MCT, which is believed to contribute to additional extrahepatic toxicity. ${ }^{21}$ Dehydromonocrotaline has the ability to alkylate cell macromolecules and causes hepatic and extrahepatic oxidative cellular damage. Synthetic dehydromonocrotaline reproduces the toxicity of MCT. ${ }^{27,28}$

In an isolated liver, dehydromonocrotaline readily conjugates with GSH to form the less toxic secondary metabolite GSDHP, ${ }^{22}$ which is excreted in high concentrations into the bile. MCT $(0.5 \mathrm{mM})$ also induces a 30 -fold increase in the biliary excretion of GSH in an isolated, perfused liver, which depletes hepatic GSH stores. ${ }^{29}$ As a result, GSH levels fall in the MCT-exposed rat liver. ${ }^{30}$

Oxidative stress occurs due to an imbalance of oxidants and antioxidants and can be quantified by evaluation of the activity of a panel of antioxidant-related enzymes. GPX is a selenium-containing antioxidative enzyme that widely exists across species and can cause detoxification of toxic superoxide to nontoxic hydroxyl compound through changing reduced GSH to oxidant glutathione. ${ }^{31}$ CAT primarily exists in the peroxisomes of aerobic cells and serves to protect cells against the toxicity of hydrogen peroxide by catalyzing its decomposition into molecular oxygen and water without producing toxic free radicals. A recent study demonstrated that CAT is a classical oxidative biomarker and is the most abundant protein in peroxisomes, where oxidative stress most frequently occurs. ${ }^{32}$ Increases in these enzyme activities suggest a response toward increased ROS generation. ${ }^{33}$

The results obtained in this study concur with other studies suggesting that increased CAT and SOD (Table 2) are common cellular defense mechanisms against ROS and oxidative stressors. These enzymes are also considered to be sensitive biomarkers for hepatic oxidative stressors. ${ }^{34}$ Cytosolic GSTs are found in almost all aerobic species and have the capacity to catalyze the conjugation of electrophilic compounds with GSH. GSTs were responsible for detoxification of exogenous substances, which suggests GST as a major target of toxicity of exogenous substances. ${ }^{35}$

The results obtained show a marked decrease in GST activity, which highlights GST as a major cellular defense mechanism against ROS. ${ }^{36} \mathrm{GR}$ is responsible for the regeneration of GSH, and GPX works together with GSH in disintegrating hydrogen peroxide and other organic hydroperoxide. ${ }^{34}$

In this study, it was shown that the administration of MCT has a direct effect on the enzymes involved in the metabolism of GSH. The administration of MCT was found to cause a significant decrease in the GR and GPX activities (Table 1), which is confirmed by the marked fall in cytosolic and mitochondrial GSH levels (Table 1). In addition, a significant increase in GPX activity in the $\mathrm{CeO}_{2}$ group may be due to the antioxidant effects of $\mathrm{CeO}_{2}$ nanoparticles, which cause a marked increase in hepatic GPXs.

Nanotechnology is a multidisciplinary field that involves the design and engineering of objects $<100 \mathrm{~nm}$ in diameter. Nanoparticles constitute a new generation of free radical scavengers and the chemistry of engineered $\mathrm{CeO}_{2}$ nanoparticles supports their potential role as biological free radical scavengers or antioxidants.

This study suggests that these nanoparticles may represent a novel therapeutic regenerative material that scavenges ROS caused by exogenously elevated ROS due to MCT exposure. When ROS are produced at high levels, cellular components are damaged. These ROS can positively affect biological systems as a defense mechanism against microorganisms and can act as signal transduction and transcription agents in development, stress responses, and programmed cell death. However, excessive oxidative stress arises from the strong cellular oxidizing potential of excess ROS, or free radicals, and has widespread adverse effects in multiple organ systems, including hepatocellular damage, increased risk of cataracts, cardiovascular disease, and cancer. ${ }^{37}$

$\mathrm{CeO}_{2}$ has a protective effect against radiation-induced oxidative damage and pneumonitis, although it has the ability to scavenge oxygen free radicals and $\mathrm{ROS}^{37}$ In addition, $\mathrm{CeO}_{2}$ 
nanoparticles offer many active sites for free radical scavenging because of their large surface/volume ratio and also the mixed valence states for unique redox chemistry. A recent article reports SOD mimetic activity of $\mathrm{CeO}_{2} \cdot{ }^{38}$ Furthermore, the free radical scavenging property of $\mathrm{CeO}_{2}$ nanoparticles is regenerative, which is not the case for other antioxidants. ${ }^{39}$ The chemical nature of $\mathrm{CeO}_{2}$ nanoparticles, in which an autoregenerative reaction cycle $\left(\mathrm{Ce}^{3+} \rightarrow \mathrm{Ce}^{4+} \rightarrow \mathrm{Ce}^{3+}\right)$ continues on the surface, is probably the mechanism by which the material gains an unprecedented free radical scavenging ability. ${ }^{37}$

$\mathrm{CeO}_{2}$ nanoparticles have been revealed to effectively protect mammalian cells against damage caused by increased ROS or nitrogen species, probably through their direct reaction with superoxide radicals, because each of these materials has been shown to act as an effective SOD mimetic in vitro. ${ }^{40}$

Dehydromonocrotaline has the ability to alkylate cell macromolecules and cause hepatic and extrahepatic oxidative cellular damage. Synthetic dehydromonocrotaline reproduces the toxicity of MCT by formation of ROS..$^{27,28}$

Results show that administration of $\mathrm{CeO}_{2}$ before and after MCT administration exerts an important protective effect as it corrects the oxidative stresses induced by administration of MCT. The experiments discussed here show that $\mathrm{CeO}_{2}$ nanoparticles were able to rescue cells from oxidative stress-induced cell damage in a manner that appears to be dependent on the structure of the particle but independent of its size within the $6-1000 \mathrm{~nm}$ range. There are three alternative explanations for the observation that the $\mathrm{CeO}_{2}$ particles protect from oxidative stress. ${ }^{41}$ They may act as direct antioxidants, block ROS production by inhibiting a step in the programmed cell death pathway, or directly cause a low level of ROS production that rapidly induces an ROS defense system before the glutamate-induced cell death program is complete. The last is a form of preconditioning that could be caused by the exposure of cells to particulate material known to induce low levels of ROS.42

The results obtained in this study were the first to demonstrate that $\mathrm{CeO}_{2}$ nanoparticles induce hepatoprotective biological responses and could be properly indicated by using a test approach such as oxidative stress.

From the current data, it can be concluded that $\mathrm{CeO}_{2}$ could be used to modulate oxidative stress and has a protecting effect against the hepatotoxicity induced by MCT administration.

\section{Acknowledgment}

This study was supported by a fund from Beni-Suef University, Egypt. We appreciate the help and advice of Dr, Prater R, VT.

\section{Disclosure}

The authors report no conflicts of interest in this work.

\section{References}

1. Chen J, Patil S, Seal S, McGinnis JF. Rare earth nanoparticles prevent retinal degeneration induced by intracellular peroxides. Nat Nanotechnol. 2006;1(2):142-150.

2. Rzigalinski BA, Bailey D, Chow L, et al. Cerium oxide nanoparticles increase the lifespan of cultured brain cells and protect against free radical and mechanical trauma. FASEB J. 2003;17(4):A606.

3. Patil S, Sandberg A, Heckert E, Self W, Seal S. Protein adsorption and cellular uptake of cerium oxide nanoparticles as a function of zeta potential. Biomaterials. 2007;28(31):4600-4607.

4. Fu PP, Xia Q, Lin G, Chou MW. Pyrrolizidine alkaloids - genotoxicity, metabolism enzymes, metabolic activation, and mechanisms. Drug Metab Rev. 2004;36(1):1-55.

5. Tarnuzzer RW, Colon J, Patil S, Seal S. Vacancy engineered ceria nanostructures for protection from radiation-induced cellular damage. Nano Lett. 2005;5(12):2573-2577.

6. Chung D. Nanoparticles have health benefits too. New Scientist. 2003; 179:2410-2416.

7. Zhang F, Wang P, Koberstein J, Khalid S, Chan SW. Cerium oxidation state in ceria nanoparticles studied with X-ray photoelectron spectroscopy and absorption near edge spectroscopy. Surf Sci. 2004;563(1-3): $74-82$.

8. Robinson RD, Spanier JE, Zhang F, Chan SW, Herman IP. Visible thermal emission from sub-band-gap laser excited cerium dioxide particles. J Appl Phys. 2002;92(4):1936-1941.

9. Copple BL, Ganey PE, Roth RA. Liver inflammation during monocrotaline hepatotoxicity. Toxicology. 2003;190(3):155-169.

10. Stegelmeier BL, Edgar JA, Colegate SM, et al. Pyrrolizidine alkaloid plants, metabolism and toxicity. J Nat Toxins. 1999;8(1):95-116.

11. Roeder E. Medicinal plants in China containing pyrrolizidine alkaloids. Pharmazie. 2000;55(10):711-726.

12. Gordon GJ, Coleman WB, Grisham JW. Induction of cytochrome P450 enzymes in the livers of rats treated with the pyrrolizidine alkaloid retrorsine. Exp Mol Pathol. 2000;69(1):17-26.

13. Xia Q, Yan J, Chou MW, Fu PP. Formation of DHP-derived DNA adducts from metabolic activation of the prototype heliotridine-type pyrrolizidine alkaloid, heliotrine. Toxicol Lett. 2008;178(2):77-82.

14. Huxtable RJ. Human health implications of pyrrolizidine alkaloids and herbs containing them. In: Cheeke PR, editor. Toxicants of Plant Origin. Vol 1. Alkaloids. Boca Raton (FL): CRC Press; 1989:41-86.

15. Huxtable RJ. Hepatic nonaltruism and pulmonary toxicity of pyrrolizidine alkaloids. In: Gram TE, editor. Metabolic Activation and Toxicity of Chemical Agents to Lung Tissue and Cells. New York: Pergamon Press; 1993:215-239.

16. Mattocks AR, Croswell S, Jukes R, Huxtable RJ. Identity of a biliary metabolite formed from monocrotaline in isolated, perfused rat liver. Toxicon. 1991;29(4-5):409-415.

17. Yan CC, Huxtable RJ. The effect of the pyrrolizidine alkaloids, monocrotaline and trichodesmine, on tissue pyrrole binding and glutathione metabolism in the rat. Toxicon. 1995;33(5):627-634.

18. Yan CC, Huxtable RJ. Effects of the pyrrolizidine alkaloid, retrorsine, on sulfur metabolism, in the liver. Proc West Pharmacol Soc. 1995;38: $37-40$.

19. Yan CC, Huxtable RJ. Effects of taurine and guanidinoethane sulfonate on toxicity of the pyrrolizidine alkaloid monocrotaline. Biochem Pharmacol. 1996;51(3):321-329.

20. Yan CC, Huxtable RJ. Quantitation of the hepatic release of metabolites of the pyrrolizidine alkaloid, monocrotaline. Toxicol Appl Pharmacol. 1994; 127(1):58-63.

21. Yan CC, Huxtable RJ. The relationship between the concentration of the pyrrolizidine alkaloid monocrotaline and the pattern of metabolites released from the isolated liver. Toxicol Appl Pharmacol. 1995; 130(1):1-8. 
22. Yan CC, Huxtable RJ. Relationship between glutathione concentration and metabolism of the pyrrolizidine alkaloid, monocrotaline, in the isolated, perfused liver. Toxicol Appl Pharmacol. 1995;130(1): 132-139.

23. Cheeke PR, Garman GR. Influence of dietary protein and sulfur aminoacid levels on the toxicity of Senecio jacobaea (tansy ragwort) to rats. Nutr Rep Int. 1974;9:197-207.

24. Miranda CL, Buhler DR, Ramsdell HS, Cheeke PR, Schmitz JA. Modifications of chronic hepatotoxicity of pyrrolizidine (Senecio) alkaloids by butylated hydroxyanisole and cysteine. Toxicol Lett 1982;10(2-3):177-182.

25. Mattocks AR. Toxicity of pyrrolizidine alkaloids. Nature. 1968; 217(5130):723-728.

26. Glowaz SL, Michnika M, Huxtable RJ. Detection of a reactive pyrrole in the hepatic metabolism of the pyrrolizidine alkaloid, monocrotaline. Toxicol Appl Pharmacol. 1992;115(2):168-173.

27. Bruner LH, Hilliker KS, Roth RA. Pulmonary hypertension and ECG changes from monocrotaline pyrrole in the rat. Am J Physiol. 1983;245(2):H300-H306.

28. Pan LC, Wilson DW, Lamé MW, Jones AD, Segall HJ. COR pulmonale is caused by monocrotaline and dehydromonocrotaline, but not by glutathione or cysteine conjugates of dihydropyrrolizine. Toxicol Appl Pharmacol. 1993;118(1):87-97.

29. Yan CC, Huxtable RJ. Effect of the pyrrolizidine alkaloid, monocrotaline, on bile composition of the isolated, perfused rat liver. Life Sci. 1995;57(6):617-626.

30. Nigra L, Huxtable RJ. Hepatic glutathione concentrations and the release of pyrrolic metabolites of the pyrrolizidine alkaloid, monocrotaline, from the isolated perfused liver. Toxicon. 1992;30(10):1195-1202.

31. Arthur JR. The glutathione peroxidases. Cell Mol Life Sci. 2000; 57(13-14):1825-1835.

32. Bocchetti R, Regoli F. Seasonal variability of oxidative biomarkers, lysosomal parameters, metallothioneins and peroxisomal enzymes in the Mediterranean mussel Mytilus galloprovincialis from Adriatic Sea Chemosphere. 2006;65(6):913-921.
33. Kyle ME, Miccadei S, Nakae D, Farber JL. Superoxide dismutase and catalase protect cultured hepatocytes from the cytotoxicity of acetaminophen. Biochem Biophys Res Commun. 1987;149(3): 889-896.

34. Lee CP, Shih PH, Hsu CL, Yen GC. Hepatoprotection of tea seed oil (Camellia oleifera Abel.) against CCl4-induced oxidative damage in rats. Food Chem Toxicol. 2007;45(6):888-895.

35. Cheeke RP. Toxicity and metabolism of pyrrolizidine alkaloids. J Anim Sci. 1988;66(9):2343-2350.

36. Liu TY, Chen Y, Wang ZY, Ji LL, Wang ZT. Pyrrolizidine alkaloid isoline-induced oxidative injury in various mouse tissues. Exp Toxicol Pathol. 2010;62(3):251-257.

37. Colon J, Herrera L, Smith J, et al. Protection from radiation-induced pneumonitis using cerium oxide nanoparticles. Nanomedicine. 2009; 5(2):225-231.

38. Heckert EG, Karakoti AS, Seal S, Self WT. The role of cerium redox state in the SOD mimetic activity of nanoceria. Biomaterials. 2008; 29(18):2705-2709.

39. Das M, Patil S, Bhargava N, et al. Auto-catalytic ceria nanoparticles offer neuroprotection to adult rat spinal cord neurons. Biomaterials. 2007;28(10):1918-1925.

40. Karakoti A, Singh S, Dowding JM, Seal S, Self WT. Redox-active radical scavenging nanomaterials. Chem Soc Rev. 2010;39(11): 4422-4432.

41. Schubert D, Dargusch R, Raitano J, Chan SW. Cerium and yttrium oxide nanoparticles are neuroprotective. Biochem Biophys Res Commun. 2006;342(1):86-91.

42. Becker S, Soukup JM, Gallagher JE. Differential particulate air pollution induced oxidant stress in human granulocytes, monocytes and alveolar macrophages. Toxicol In Vitro. 2002;16(3):209-218.
International Journal of Nanomedicine

\section{Publish your work in this journal}

The International Journal of Nanomedicine is an international, peerreviewed journal focusing on the application of nanotechnology in diagnostics, therapeutics, and drug delivery systems throughout the biomedical field. This journal is indexed on PubMed Central,

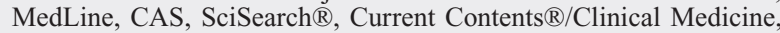

\section{Dovepress}

Journal Citation Reports/Science Edition, EMBase, Scopus and the Elsevier Bibliographic databases. The manuscript management system is completely online and includes a very quick and fair peer-review system, which is all easy to use. Visit http://www.dovepress.com/ testimonials.php to read real quotes from published authors. 